\title{
Intrathecal Pumps
}

\author{
Shawn Belverud, Alon Mogilner, and Michael Schulder
}

Department of Neurosurgery, North Shore LIJ Health System, Manhasset, New York 11030

\begin{abstract}
Summary: Direct neuroaxis drug delivery has expanded the physician's armamentarium to provide treatment options to those who have failed more conservative interventions. Starting from Bier's 'cocainization of the spinal cord' in 1898, direct nervous system pharmacy delivery has long been recognized as an effective means to treat pain. Intrathecal pump systems are now commonplace in the management of numerous pain states, as well as of neuromuscular sequelae of central nervous system injury. There has been much advancement in the physiologic and pharmacologic understanding of direct neuromodulation, providing a growing number
\end{abstract}

of treatment options depending on the specific disease state. As well, surgical techniques and catheter systems have undergone refinements providing improved long-term safety and efficacy. We present a review of the historical evolution to current intrathecal therapies, as well as a dialog regarding patient selection, drug options, and side effects. Also, included is a discussion of surgical techniques, current delivery options and complications concerning pump placement. Key Words: Intradural narcotics, intrathecal narcotics, intraventricular drug delivery, neuropathic pain, nociceptive pain.

\section{INTRATHECAL THERAPIES}

Intrathecal drug delivery has evolved into a therapeutic modality available to those who have failed more conservative interventions. Initially reserved for those suffering from debilitating malignant pain or severe spasticity, clinical indications continue to expand for this form of neuromodulation. From these initial indications, direct delivery of drug to the neural axis has proven to be adaptable to other pathologic states as well. This article offers a review of both intrathecal (IT) pain and spasticity management, with a brief review of newly developing therapies. Also included is a discussion of pump systems, as well as surgical techniques and strategies.

\section{Intrathecal pain management}

John Milton wrote in Paradise Lost that "pain is perfect miserie, the worst of evils, and, excessive, overturns all patience." The sensation of pain is something that unites all persons and forgets none, although the resilience of certain types of pain to traditional therapeutics has fostered the need for other modalities. The physician's medical armamentarium to treat pain is extensive and in many cases effective with traditional routes. When

Address correspondence and reprint requests to: Michael Schulder, M.D., Department of Neurosurgery, North Shore University Hospital, 300 Community Drive, 9 Tower, Manhasset, NY 11030. E-mail: Schulder@nshs.edu. oral or parenteral routes provide insufficient relief, analgesics may be delivered directly to the central nervous system.

The obvious advantage of this method is that direct IT delivery of morphine yields a much increased relative strength of drug compared to its oral or intravenous equivalent. Finding the true ratio of IT to oral morphine has been challenging, as is reflected in the disparate conversions in the literature ranging from $12: 1$ to $300: 1{ }^{1}$ No matter the equation, the decrease in systemic drug levels as provided by IT therapy reduces side effects and practically eliminates undesirable metabolic by-products, specifically morphine-3-glucuronide (M3G).

August Bier performed 'cocainization of the spinal cord' in 1898, and numerous reports appeared describing the use of IT phenol for cancer pain throughout the 1960s. ${ }^{2}$ However, it was not until 1976, when Yaksh and Rudy $^{3}$ published their animal study on IT morphine for the management of pain, that neurosurgeons began to explore this concept in practice. Evidence that direct neuroaxis morphine delivery dramatically reduced pain in rats and primates led to human clinical trials and case reports that showed efficacy in numerous pain states. The human application was promoted by the fact that direct IT morphine offered greater control of drug levels and rapid reversibility, produced fewer side effects, and offered superior pain control for certain refractory pain types. $^{4}$ 
In the early 1980s, Rico et al. ${ }^{5}$ and Leavens et al. ${ }^{6}$ both reported satisfactory analgesic effects with minimal side effects in patients treated with boluses of IT morphine. Both groups reported moderate to significant pain relief in a majority of the cancer patients studied (Rico et al., 78\%; Leavens et al., and 66\%), using individual IT injections of morphine. This work, along with similar studies, led to the rapid approval of IT delivery of morphine, as well as to a search for other types of pain amenable to IT delivery.

Studies concerning nononcologic chronic pain patients proceeded, and in 1985 Auld et al. ${ }^{7}$ reported $65 \%$ of 43 patients with good to excellent pain control. Numerous studies of small to moderate size followed, and in 1996 Paice et al. ${ }^{8}$ published a multicenter retrospective study involving 429 patients, two thirds of whom had a diagnosis other than cancer. The overall results in the chronic pain patients, made up chiefly of failed back surgery patients, were equal to those of the cancer patients, with patients having somatic pathology responding better treated than those whose pain was purely neuropathic. ${ }^{8}$ (Somatic pain is the dull, achy discomfort arising from the musculoskeletal system and neuropathic pain is often burning in nature, resulting from a lesion or injury to the nerve itself.)

Other studies have offered further support for chronic pain patients, expanding from morphine monotherapy to combinations of local anesthetics and alpha-2 agonists. ${ }^{9,10}$ Initially focused on failed back syndrome, indications have now expanded to include complex regional pain syndrome, postherpetic neuralgia and painful peripheral neuropathy. ${ }^{11}$

The rapid advent of IT analgesic delivery required the technology to support continuous infusion to provide prolonged, constant levels and to maximize therapeutic effects while limiting side effects. Early studies described individual responses to externally delivered boluses of morphine, not continuous infusion. ${ }^{12}$ These crescendo-decrescendo delivery methods both exacerbated side effects and exposed the patients to the greater risk of infection, as well as CSF leaks. In response, the Shiley Infusaid pump (Norwood, MA) was used as the first implantable continuous infusion pump, followed by the first implantable programmable pump, SynchroMed (Medtronic, Minneapolis, MN), approved by the FDA in $1991 .^{13}$ Now, including the newest generation pump, SynchroMed II, more than 50,000 pumps worldwide have been implanted, with the primary indication now being nonmalignant, chronic pain. (Specifics regarding surgical techniques for pump placement will be offered later in this review.)

\section{Patient selection for intrathecal narcotics}

The key to success in any surgical treatment is the correct assessment of procedure benefit—and avoiding iatrogenic exacerbation of the patient's medical condition. As a rule, patients considered for a neuromodulation procedure should first undergo the full extent of oral analgesic therapy in the accordance of multidisciplinary care. Under optimized medical therapy, with concomitant use of both short- and long-acting analgesics, $>90 \%$ of patients will attain adequate pain control. ${ }^{14}$ Only patients who fail to respond to high-dose systemic medication administration or those with intolerable side effects are appropriate for IT management.

Multiple factors must be accurately defined during this period, including the patient's psychological history, support system, pathophysiologic etiology of the pain, and issues related to secondary gain. Life expectancy is another important consideration, pertaining more to cancer patients. Cost analysis indicates that IT delivery is the most cost-effective mode of opioid delivery for patients requiring long-term management for cancer ( $\geq 3-6$ months) and nonmalignant ( $\geq 11-22$ months) pain. ${ }^{15}$ If life expectancy is likely to be shorter, external delivery systems may be simpler, and certainly are less expensive. Furthermore, surgeons must consider and explain such possible complications as CSF leaks or infections extending to and involving the CNS, as well as the need for continued refills of the pump.

Once the patient has gone through the initial assessment for IT opioids, an IT trial is necessary to determine if the patient will gain analgesic benefit. This can be done either by placing a single bolus via lumbar puncture or (especially in those who have had been on high-dose opioids for extended periods of time) by means of an external delivery system that allows continuous, titratable infusion over a predetermined time period. Concomitant use of oral analgesics should continue through this period, because of the possibility that the assessment of IT response may be confounded by symptoms of narcotic withdrawal.

After the trial, the patient should be in a monitored setting with vigilant nursing care, pulse oximetry, and hourly neurological checks in the event that respiratory depression should occur. Naloxone should also be readily available. Given the water-soluble pharmacokinetics of morphine, onset of action should occur in approximately 30 min to $1 \mathrm{~h}$, with effects lasting $18-24 \mathrm{~h}^{16}$ Prescribing clinicians should consider the conversion of oral narcotic doses to their IT equivalents. Typically, to convert from the patient's systemic medication dose, divide by 300 for oral medication and 100 for parenteral dosing. For example, $1 \mathrm{mg}$ of IT morphine a day would be equianalgesic to $300 \mathrm{mg}$ of oral morphine or $100 \mathrm{mg}$ given intravenously.

Although side effects are often reduced in this population given the usual chronic history of opioid use, they can and do occur. Constipation is quite common along with urinary retention. ${ }^{17}$ Pruritus is also frequently en- 
countered but most usually abates over $12-24 \mathrm{~h}$. Myoclonus, usually developing over months after the commencement of treatment, may necessitate dose reduction. Hydromorphone should be considered for patients with resilient pruritus and has been shown to have a lower incidence of myoclonus. ${ }^{18}$ Chronic urinary retention can typically be relieved by decreasing IT dosing. ${ }^{19}$ Endocrinologic suppression of both male and female sex hormones may also occur, requiring supplementation. ${ }^{20}$ Not uncommonly, persistent dependent edema can also arise that is not readily amenable to diuretics, and some authors consider pre-existing venous insufficiency to be a relative contraindication to IT narcotic administration. ${ }^{21}$

Many of the early animal studies showing rapid tolerance to IT morphine injections are likely due in part to the large doses given. ${ }^{22}$ This problem is less likely to occur in clinical use, because patients rarely require rapid increases in dosing. Generally speaking, small increments are needed over months to years and should not incite concern. Initial efficacy followed by the need for higher doses over the ensuing weeks to months, however, should raise the possibility of opioid tolerance, or perhaps a pump delivery system malfunction.

Whereas morphine, baclofen, and ziconotide (see below) are currently the only agents approved by the U.S. Food and Drug Administration (FDA) for use in IT pumps, other narcotic and non-narcotic agents are now routinely used, both individually and in combination. ${ }^{23-25}$ Common agents now in use include hydromorphone and fentanyl as narcotic alternatives to morphine, as well as clonidine, bupivacaine, and ziconotide, an $\mathrm{N}$-type specific calcium channel blocker, for neuropathic pain syndromes. The reader is referred to the Polyanalgesic Consensus Conference statement, ${ }^{25}$ which outlines drug selection algorithms and reviews the side-effect profile of these various individual agents. For example, practitioners considering IT clonidine should be cognizant of the underlying cardiovascular effects (specifically, rebound hypertension if therapy is abruptly ceased).

\section{Intrathecal baclofen}

Baclofen, or 4-amino-3-(4-chlorophenyl)-butanoic acid, is a synthetic pre- and postsynaptic $\gamma$-aminobutyric acid receptor type $\mathrm{B}\left(\mathrm{GABA}_{\mathrm{B}}\right)$ agonist. Its receptors are located in high concentration of laminas II and III of the dorsal gray matter horns of the spinal cord. ${ }^{26}$ The actions of baclofen are mediated by G-proteins, and the presynaptic binding restricts calcium influx and postsynaptic binding increases potassium conductance resulting in hyperpolarization. ${ }^{27,28}$ Not only does this decrease excitatory synaptic release of neurotransmitters such as aspartate and glutamate, but also substance $\mathrm{P}$ in nociceptive afferent nerve endings thought to cause painful flexor spasms. $^{29}$
Baclofen was originally developed in the 1920s for use as an antiepileptic. Despite its poor efficacy in seizure management, observant clinicians noticed a decreased tonicity in spastic patients being treated for seizures. Such observations led to abandonment of baclofen for seizure treatment, and by the 1970 s its primary use was as an oral agent in the management of spasticity. The effectiveness of oral baclofen, despite ready absorption through the gastrointestinal tract, is attenuated because its high hydrophilicity results in very low CNS penetration. In fact, oral baclofen doses of 30-60 mg yield IT levels of 12-96 $\mu \mathrm{g}$. Raising oral levels of baclofen ultimately leads to side effects, most commonly sedation, but also confusion, urinary frequency, and insomnia. The next idea was that direct delivery of baclofen to the neuroaxis, via the thecal sac, could maximize therapeutic response and also diminish side effects.

In the mid-1980s, Penn and Kroin and colleagues provided the first report of IT baclofen, ${ }^{30}$ which was followed by a double-blinded study 5 years later involving adults with spinal spasticity secondary to multiple sclerosis or spinal injury. ${ }^{31}$ Results displayed a decrease in the Ashworth score (a spasticity rating scale) in all 20 patients of the treatment arm, as well as a reduction of spasticity in $95 \%$. The first report of a pediatric patient receiving IT baclofen was published by Dralle et al. ${ }^{32}$ in 1985, who described the case of a 4-year-old boy rendered spastic from global ischemia after a near-drowning injury. This was followed by two studies in the early 1990s by Müller ${ }^{33}$ and Albright et al. ${ }^{34}$, both demonstrating a decrease in spasticity and dystonia.

\section{Patient selection for intrathecal baclofen}

As with the direct neuroaxis delivery for pain management, those undergoing consideration for IT baclofen should undergo maximized oral management under multidisciplinary guidance, including specialists in neurology, physiatry, neurosurgery, and, for some patients, orthopedics as well. Physical therapy evaluation is necessary to assess spasticity, with most patients having Ashworth scores of 3-4 or greater in the upper and lower extremities (which means that spasticity is impeding care, function, or both). Goals of increased functionality, decreased contractures, care facilitation, and overall comfort should be discussed, as well as the need for continued refills of the pump. Contraindications to IT catheter placement include poor compliance and unrealistic expectations of the procedure.

Most young children under the age of 4 years respond well to oral baclofen for moderate to even severe symptoms, and pump placement is rarely warranted. Determining the etiology of the spasticity is critical for therapeutic benefit. Generally speaking, patients with spastic diplegia secondary to spinal cord injury or familial spastic paraparesis benefit from IT baclofen. Notably, IT baclofen also displays efficacy in the treatment of pa- 
tients with severe spastic hemiplegia, in whom the spasticity responds well without producing a contralateral hypotonia.

There is a growing body of work supporting the use of IT baclofen in patients with spasticity of cerebral origin, specifically for the moderate to severe diplegic and tetraplegic spasticity of cerebral palsy. ${ }^{35,36}$ For those patients, typically between the ages of 4 and 10, who have pure spastic diplegia (i.e., no symptoms of dystonia) with retained muscle strength and the ability to ambulate, selective dorsal rhizotomy should be considered as surgical treatment.

Children with dystonia and mixed spasticity from cerebral injury also respond well to IT baclofen. Albright et al. ${ }^{37}$ reported in 2001 that ease of care and quality of life improved in 86\%, and speech improved in $33 \%$ of 77 patients who had undergone pump placement. Secondary dystonias resulting from brain injury respond better than does primary syndromal dystonia, which is best treated with deep brain stimulation. ${ }^{38}$ Children with hemidystonia often respond in a similar fashion to their spastic counterparts, displaying good outcomes.

The adult population has also found benefit across a gamut of spastic etiologies, most commonly after spinal cord injury, multiple sclerosis, spasticity following ischemic stroke, and spondylitic myelopathy. ${ }^{39}$ Ben Smail et al. ${ }^{40}$ showed good efficacy in multiple sclerosis patients, with sustained benefit in 64 patients despite an advanced stage of disease. Other similar studies have displayed similar efficacy in regard to other spastic causes.

Once the patient or caregivers (or both) understand the goals of IT baclofen and the patient is deemed to be a good surgical candidate, it is necessary to perform a trial via a lumbar tap or placement of a thecal catheter with an external pump. For a single-bolus technique, drug is injected in the operating room and then the patient is watched in the recovery room until stable. A bolus typically provides maximal benefit to the lower extremities at $\sim 60 \mathrm{~min}$, affects the upper extremities at $2 \mathrm{~h}$, and has maximal affects at $4 \mathrm{~h}$, with the effects waning at $8-10 h .^{41,42}$ Using these time frames, the patient should be assessed by physical therapy, or a member of the surgical team with knowledge of the Ashworth scale, for clinical improvement. If the patient has responded to the test injection with diminished spasticity, he or she is returned the following day for definitive pump placement. If the patient experienced any significant lethargy after the bolus, the concentration of the baclofen solution in the pump should be diluted accordingly, to allow for appropriate dosing.

The list of side effects with IT baclofen continues to grow as our experience grows, with reports of $10-75 \%$ of patients having some complication, most of mild severity. These complications can be broken down into two large subgroupings: those resulting from the drug itself and those related to the catheter-pump system. Lethargy is the most common drug side effect, with bradycardia and respiratory depression occurring less frequently; these usually can be modulated by titration of drug rate. There are reports of new-onset seizures after introduction of the IT baclofen, but nearly all describe patients after significant head trauma. ${ }^{43}$ In fact, Buonaguro et al. ${ }^{44}$ recently reported a reduced seizure rate of $13 \%$ in 150 children studied, with two patients worsening and one experiencing new onset ictus. Additionally, there are reports of scoliosis exacerbation after IT baclofen. ${ }^{45}$ The exact cause-and-effect relationship is not clear; however, the change in muscle tonicity may be playing a role.

\section{SURGICAL TECHNIQUES}

\section{Presurgical planning}

The choice of implanted hardware is based on a number of factors, including the size and weight of the patient and the expected drug concentration and dose. Most patients will receive a programmable catheter and pump system (FIG. 1). Nonprogrammable pumps are available at lower cost (e.g., Medtronic's IsoMed pump). These should be reserved for patients undergoing pump replacement, those who have been on stable medication doses for a long period of time, and those who do not expect any dose escalations or reductions that would require complete emptying of the pump and catheter.

A number of different catheters, one- or two-piece, are available (FIG. 2). The one-piece catheter is simpler to implant and requires fewer connections, but some prefer the larger outer diameter of the two-piece proximal catheter and believe it is less prone to kinking or obstruction. Some have suggested that the two-piece catheter system

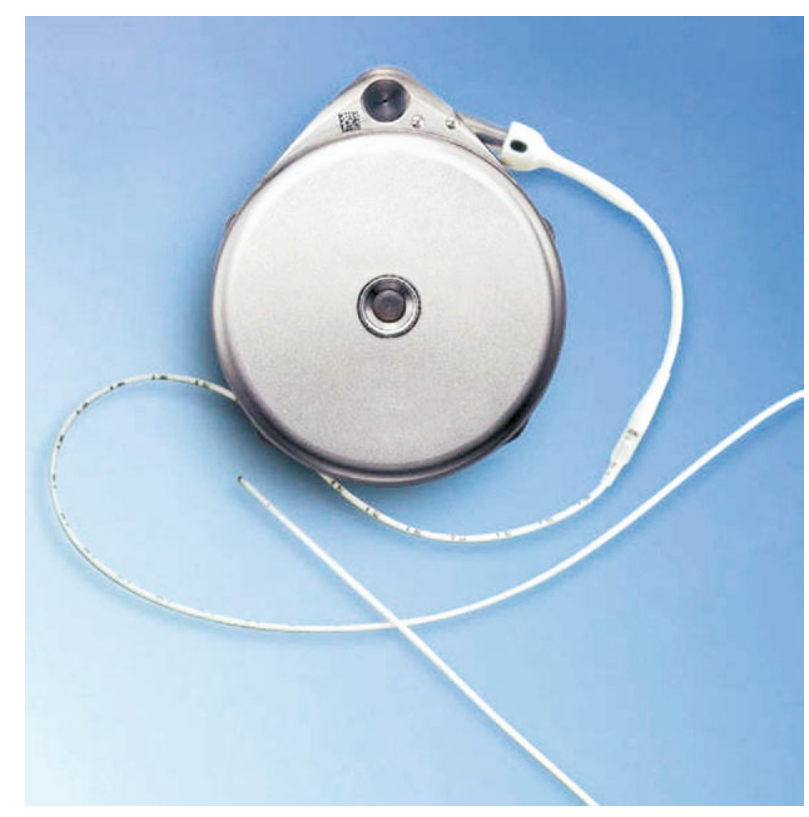

FIG. 1. Medtronic SynchroMed II pump and one-piece sutureless catheter (photo courtesy of Medtronic, Minneapolis, MN). 


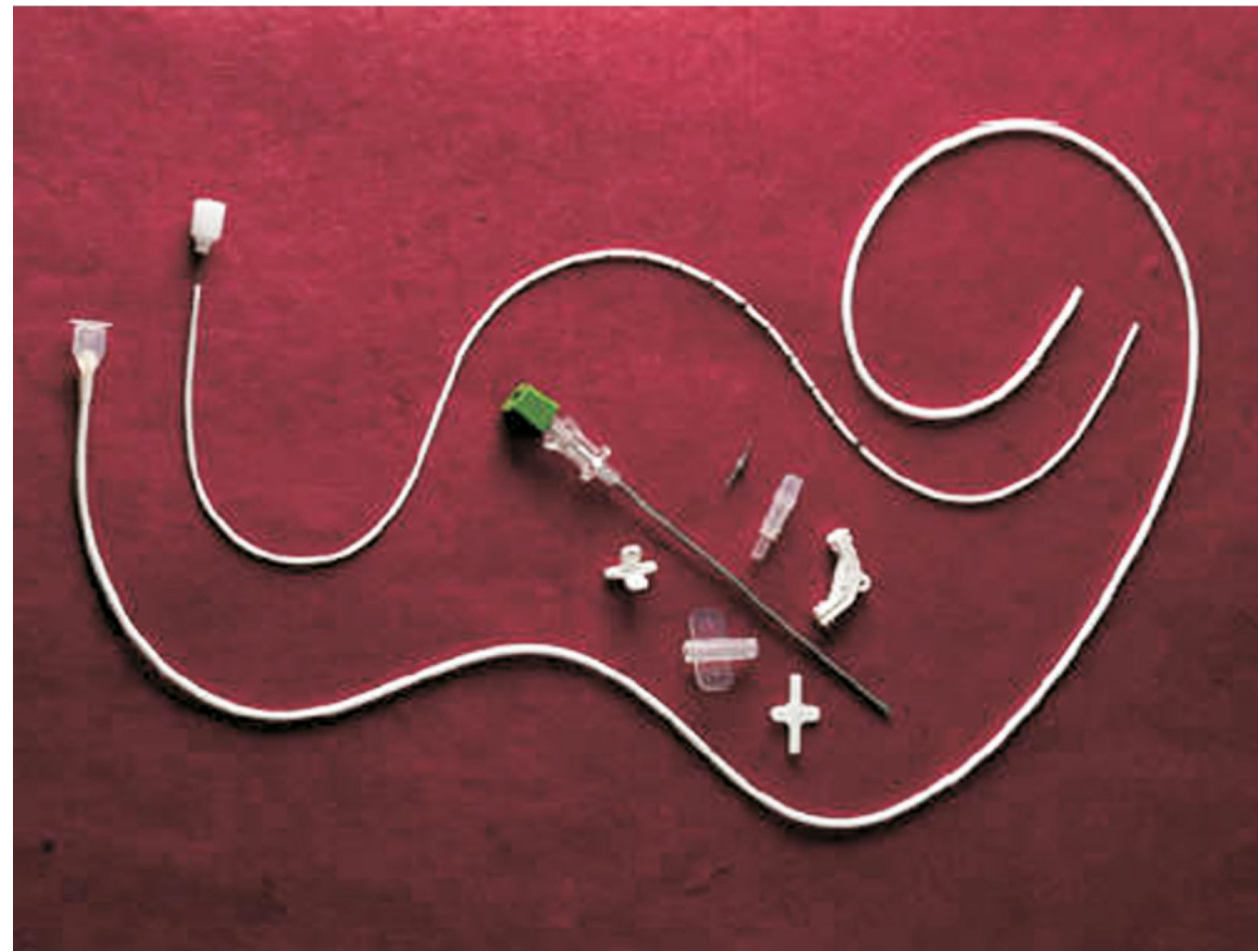

FIG. 2. Medtronic 2-piece catheter system and accessories: InDura free-flow intrathecal catheter model 8711. See http://www.medtronic. $\mathrm{com} /$ neuro/paintherapies/pain_treatment_ladder/drug_infusion/pumps_pump_sel/intrathecal_catheters.html (photo courtesy of Medtronic, Minneapolis, MN).

is less likely to migrate out of the IT space. Furthermore, IT catheter revisions are slightly easier with the twopiece system. Our preference is to use the two-piece catheter for those patients who are ambulatory or physically active, with the rationale being that the one-piece catheter may be more prone to malfunction in active patients.

The location of the catheter tip depends on the condition being treated and the medication or medications used. ${ }^{46}$ There is evidence that a higher catheter tip location can result in improved upper extremity spasticity scores. ${ }^{47}$ For pain treatment, placement of the catheter tip near the level of the pain may be more important when using analgesic agents that are lipophilic and penetrate further and fasting into biological tissue than do hydrophilic agents.

The pump itself is placed subcutaneously in the anterior abdominal wall, although it can be placed more laterally or even in the gluteal region if necessary. Prior incisions, as well as patient preference, may dictate the most appropriate implant site. The SynchroMed II pump is available in both $20 \mathrm{~mL}$ and $40 \mathrm{~mL}$ sizes, selection of the appropriate size pump should take into account the patient's size and weight, as well as the pharmacologic agent used and the expected refill interval. In particularly young or thin individuals, subfascial placement of the pump provides an excellent cosmetic result, with a lower risk of wound breakdown. ${ }^{48}$

\section{Implant technique}

The surgery itself can be performed under general or local anesthesia, in the lateral decubitus position (FIG. 3 ). We use fluoroscopic guidance for all our catheter implants, to assure appropriate placement of the catheter tip without looping or kinking. The Tuohy needle supplied with the catheter is used to enter the lumbar IT space via an oblique paramedian approach, which can facilitate catheter placement and minimize the incidence of catheter shear compared to placement at the midline through the interspinous ligament. Once CSF flow is noted, the catheter is then advanced to the appropriate level under fluoroscopic guidance. Subsequently, a linear cut-down is made above and below the needle down to the lumbodorsal fascia or to the supraspinous ligament. A nonabsorbable suture is used to fashion a purse-string suture around the needle entry point, to minimize catheter movement and possible CSF leakage. After removing the needle and stylet, CSF flow is confirmed at the catheter tip, the purse-string suture is tied, and CSF flow is confirmed once again to make sure that the stitch did not kink the catheter. A silicone elastomer anchor is then used to anchor the catheter to the fascia.

The pump pocket is then fashioned in the appropriate location. We make certain that we mark the incision while the patient is still supine. There can be significant shifting of the soft tissue, especially in larger patients, after placing the patient in the lateral decubitus position. 


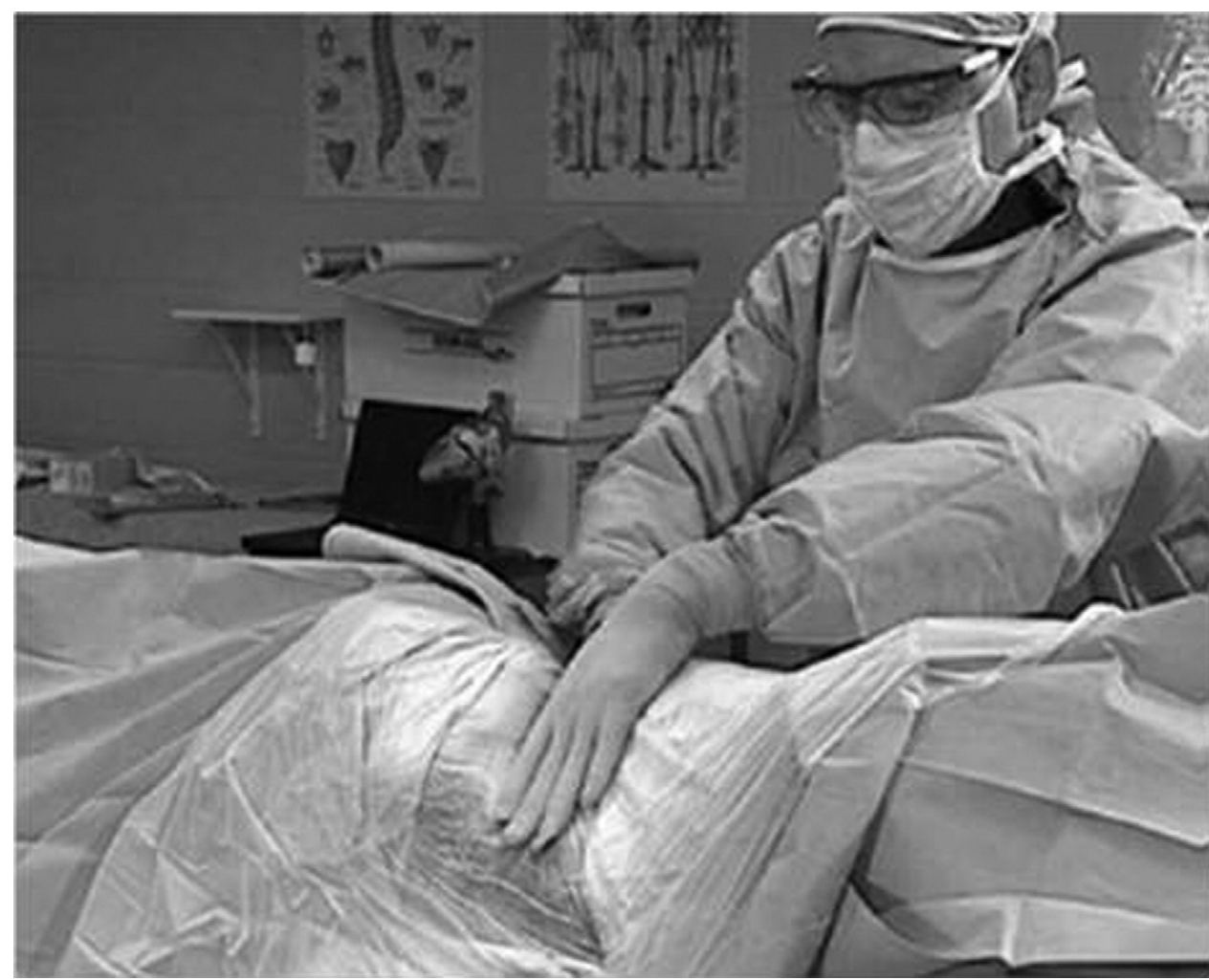

FIG. 3. Patient positioned in the lateral position and prepped for catheter and pump implantation (photo courtesy of Medtronic, Minneapolis, MN).

For obese individuals, care must be taken to avoid overly deep placement of the pump, as it may result in difficulty refilling. If the placement is subfascial, a plane is developed between the rectus fascia and muscle using blunt dissection. The fascial band known as the semicircular line will need to be divided to ensure an adequately sized pocket.

Once the pocket has been formed, a catheter passer is then used to pass the catheter from one incision to the other. When a two-piece catheter is used, the pieces are connected, and a plastic strain-relief sleeve is placed over the connection, which is usually left in the lumbar wound and anchored to the fascia.

The pump is then prepared appropriately, and may be placed in a Dacron pouch according to the surgeon's preference (although it is important to note that these can calcify and later impede refilling). The distal catheter is then trimmed appropriately, leaving sufficient catheter coiled behind the pump as a strain relief to allow for normal movement. It is then connected to the pump with the appropriate connector, which may or may not require one or more sutures, depending on the particular connector used. At the conclusion of the case, the pump is programmed to deliver the appropriate priming dose and daily dose.

\section{Postoperative management}

Postoperative management varies from center to center, as some surgeons prefer to leave patients flat in bed for 24-48 $\mathrm{h}$ to minimize the incidence of CSF leakage, whereas others discharge on the same day. Adjustment of pump dosing is done according to the individual surgeon's preference.

\section{COMPLICATIONS}

Aside from incisional pain, which is usually well tolerated, patients may report positional headaches consistent with CSF leakage. Although most of these will resolve conservatively, occasionally an epidural blood patch, performed under fluoroscopy to avoid inadvertent catheter damage, may be indicated. Transcutaneous leakage of CSF through the lumbar wound is an indication for urgent surgical exploration. The onset of acute nonincisional type pain may suggest damage to the nerve roots, spinal cord, or both. ${ }^{49}$ Pump pocket seromas may occur; these are usually treated conservatively. CSF collections may be seen following surgery at the catheter entry site and may track forward to the pump pocket. Again, conservative management is recommended; these may resolve over a period of weeks to months. Persistent CSF collections should require investigation into undi- 
agnosed causes of increased CSF pressure (hydrocephalus, pseudotumor cerebri). Furthermore, one must always rule out a catheter leak or disconnect as a source of a postoperative fluid collection. Replacement of the IT catheter at a different level may be the only way to eliminate a persistent CSF fistula around the catheter exit site.

Infection of the implant will usually require device removal, although a number of authors have reported successful in situ treatment of infected pumps. ${ }^{50,51}$

Malfunction of the drug delivery system is initially a clinical diagnosis. Confirmation of a malfunction can be obtained via radiography demonstrating a catheter disconnect or breakage. Easy aspiration of CSF via the catheter access port suggests that the catheter is patent. Injection of myelographic contrast media can be performed to confirm delivery to the IT space. Aspiration of the pump reservoir may reveal a larger quantity of drug than is predicted, suggesting a blockage to flow. Although these and other diagnostic studies can be used as confirmation of a malfunction, clear clinical findings in the presence of normal radiographic studies should warrant surgical exploration of the system. Abrupt cessation of IT baclofen therapy can result in life-threatening baclofen withdrawal, with symptoms of hyperthermia, tachycardia, hypertension, seizures, altered mental status, and psychomotor agitation. ${ }^{52,53}$ Oral baclofen replacement is not always successful, and immediate resumption of IT baclofen delivery via pump revision or via external catheter may be indicated.

The use of highly concentrated narcotic and non-narcotic analgesics has been associated with the formation of catheter granulomas, which are inflammatory masses at the tip of the IT catheter that may cause pain or neurologic deficit secondary to spinal cord compression. ${ }^{54-56}$ Clinicians should be alert for new-onset radicular pain with or without sensory and motor deficits in these patients. Magnetic resonance imaging will demonstrate the mass at the catheter tip. If the patient has no significant motor deficit, the granuloma may resolve on its own if the therapy is discontinued or if the agent is switched to a lower concentration. Surgical exploration is thus indicated only in acute neurologic deficit secondary to neural compression.

Medication overdose can occur with either opioids or baclofen, due to injection next to the pump or into the side port when trying to refill it, or due to changes in programming. Suspected drug overdose should be treated with immediate deactivation of the pump and administration of naloxone for narcotic agents and physostigmine for baclofen overdose, as well as airway protection with intubation if necessary. A high-volume lumbar puncture will facilitate rapid removal of remaining drug in the CSF space. Inadvertent subdural (as opposed to subarachnoid) placement of the catheter and drug de- livery, followed by delayed communication between the two spaces, has been reported as an uncommon cause of overdose. $^{57}$

\section{INTRAVENTRICULAR PUMPS}

In selected patients, the placement of an intraventricular delivery system may be considered. If pain is diffuse (especially in patients with cancer) or involves the upper body, greater efficacy may be achieved by targeting opioid receptors in the brain. ${ }^{58}$ The simplest and most commonly described technique involves placing a catheter via a precoronal burr hole into the frontal or lateral ventricle. ${ }^{59}$ As is true with intraspinal IT catheters, medication may be administered via bolus injections into a subcutaneous reservoir, or with the aid of an implanted pump. ${ }^{60}$

Surgical technique of an intraventricular pump system is equivalent to that of an intraspinal device, with obvious changes such as the patient being positioned supine. Surgical complications likewise are in general the same, especially the risk of infection and the need for device explantation; to this must be added the small risk of intracerebral or intraventricular hemorrhage from catheter insertion. Side effects of drug delivery are also equivalent, with perhaps a higher likelihood of nausea and respiratory depression. ${ }^{61}$

The relative technical ease of the procedure and the severity of certain neurological disorders have led to a variety of human trials or animal studies using intraventricular infusion. These have included patients with Alzheimer's disease and animal models of storage diseases and spongiform encephalopathies (such as CreutzfeldtJakob disease). ${ }^{62-64}$ These preliminary efforts hold out the possibility that neurosurgical therapies as yet unimagined may be brought to bear on diseases now considered untreatable.

\section{CONCLUSION}

Surgeons provide valuable insight into the treatment of patients with pain of malignant or other origin, chronic neurologic injury leading to spasticity, and other disease states difficult to treat but amenable to IT modalities. Neuromodulation in the form of direct neuroaxis drug delivery offers excellent therapeutic benefice and cost efficiency to properly selected patients. Under skilled hands, the complications of implanting these devices are minimized and the patient's quality of life is often dramatically improved. 59

Disclaimer: S.A.B. is a military service member (DO LT USN MC). This work was prepared as part of his official duties. Under the copyright act of 1976, Title 17 U.S. Code Section 105, copyright protection under this title is not available for any work of the U.S. Gov- 
ernment. The views expressed in this article are those of the author and do not necessarily reflect the official policy or position of the Department of the Navy or the Department of Defense, nor the U.S. Government.

\section{REFERENCES}

1. Lindsay SM. The conversion challenge: from intrathecal to oral morphine. Am J Hosp Palliat Care 2004;21:143-147.

2. Brill S, Gurman GM, Fisher A. A history of neuraxial administration of local analgesics and opioids. Eur J Anaesthesiol 2003;20: 682-689.

3. Yaksh TL, Rudy TA. Analgesia mediated by a direct spinal action of narcotics. Science 1976;192:1357-1358.

4. Simpson RK Jr. Mechanisms or action of intrathecal medications. Neurosurg Clin N Am 2003;14:353-364.

5. Rico RC, Hobika GH, Avellanosa AM, Trudnowski RJ, Rempel J, West CR. Use of intrathecal and epidural morphine for pain relief in patients with malignant diseases: a preliminary report. J Med 1982;13:223-231.

6. Leavens ME, Hill CS Jr, Cech DA, Weyland JB, Weston JS. Intrathecal and intraventricular morphine for pain in cancer patients: initial study. J Neurosurg 1982;56:241-245.

7. Auld AW, Maki-Jokela A, Murdoch DM. Intraspinal narcotic analgesia in the treatment of chronic pain. Spine 1985;10:777-781.

8. Paice JA, Penn RD, Shott S. Intraspinal morphine for chronic pain: a retrospective, multicenter study. J Pain Symptom Manage 1996; 11:71-80.

9. Nitescu P, Dahm P, Appelgren L, Curelaru I. Continuous infusion of opioid and bupivacaine by externalized intrathecal catheters in long-term treatment of "refractory" nonmalignant pain. Clin J Pain 1998; 14:17-28.

10. Brogan SE. Intrathecal therapy for the management of cancer pain. Curr Pain Headache Rep 2006;10:254-259.

11. Kaplan KM, Brose WG. Intrathecal methods. Neurosurg Clin N Am 2004;15:289-296, vi.

12. Brazenor GA. Long term intrathecal administration of morphine: a comparison of bolus injection via reservoir with continuous infusion by implanted pump. Neurosurg 1987;21:484-491.

13. Krames E. Implantable devices for pain control: spinal cord stimulation and intrathecal therapies. Best Pract Res Clin Anaesthesiol 2002;16:619-649.

14. Penn RD. Intrathecal medication delivery. Neurosurg Clin N Am 2003;14:381-387.

15. Hassenbusch SJ, Paice JA, Patt RB, Bedder MD, Bell GK. Clinical realities and economic considerations: economics of intrathecal therapy. J Pain Symptom Manage 1997;14(3 Suppl):S36-S48.

16. France JC, Jorgenson SS, Lowe TG, Dwyer AP. The use or intrathecal morphine for analgesia after posterolateral lumbar fusion: a prospective, double-blind, randomized study. Spine 1997;22:2272-2277.

17. Jacobson L, Chabal C, Brody MC. A dose-response study of intrathecal morphine: efficacy, duration, optimal dose and side effects. Anesth Analg 1988;67:1082-1088.

18. Anderson VC, Cooke B, Burchiel KJ. Intrathecal hydromorphone for chronic nonmalignant pain: a retrospective study. Pain Med 2001;2:287-297.

19. Uppal GS, Haider TT, Dwyer A, Uppal JA. Reversible urinary retention secondary to excessive morphine delivered by an intrathecal morphine pump. Spine 1994;19:719-720.

20. Abs R, Verhelst J, Maeyaert J, et al. Endocrine consequences of long-term intrathecal administration of opioids. J Clin Endocrinol Metab 2000;85:2215-2222.

21. Aldrete JA, Couto da, Silva JM. Leg edema from intrathecal opiate infusions. Eur J Pain 2000;4:361-365.

22. Yaksh TL, Kohl RL, Rudy TA. Induction of tolerance and withdrawal in rats receiving morphine in the spinal subarachnoid space. Eur J Pharmacol 1977;4:275-284.

23. Wermeling DP, Berger JR. Ziconotide infusion for severe chronic pain: case series of patients with neuropathic pain. Pharmacotherapy 2006;26:395-402.
24. Hassenbusch SJ, Gunes S, Wachsman S, Willis KD. Intrathecal clonidine in the treatment of intractable pain: a phase I/II study. Pain Med 2002;3:85-91.

25. Hassenbusch SJ, Portenoy RK, Cousins M, et al. Polyanalgesic Consensus Conference 2003: an update on the management of pain by intraspinal drug delivery-report of an expert panel. J Pain Symptom Manage 2004;27:540-563.

26. Price GW, Wilkin GP, Turnbull MJ, Bowery NG. Are baclofensensitive $\mathrm{GABA}_{\mathrm{B}}$ receptors present on primary afferent terminals of the spinal cord? Nature 1984;301:71-74.

27. Kerr DIB, Ong J. GABA $A_{B}$ receptors. Pharmacol Ther 1995;67: $187-246$

28. Zieglgänsberger W, Howe JF, Sutor B. The neuropharmacology of baclofen. In: Müller H, Zierski J, Penn RD, editors. Local-spinal therapy of spasticity. Berlin: Springer-Verlag, 1988:37-49.

29. Young RR, Delwaide PJ. Drug therapy: spasticity (second of two parts). N Engl J Med 1981;304:96-99.

30. Penn RD, Kroin JS. Intrathecal baclofen alleviates spinal cord spasticity. Lancet 1984;1(8385): 1078.

31. Penn RD, Savoy SM, Corcos D, et al. Intrathecal baclofen for severe spinal spasticity. N Engl J Med 1989;320:1517-1521.

32. Dralle D, Müller H, Zierski J, Klug N. Intrathecal baclofen for spasticity. Lancet 1985;2(8462):1003.

33. Müller H. Treatment of severe spasticity: results of multi-center trial conducted in Germany involving the intrathecal infusion of baclofen by an implantable drug delivery system. Dev Med Child Neurol 1992;34:739-745.

34. Albright AL, Cervi A, Singletary J. Intrathecal baclofen for spasticity in cerebral palsy. JAMA 1991;265:1418-1422.

35. Bleyenheuft C, Filipetti P, Caldas C, Lejeune T. Experience with external pump trial prior to implantation for intrathecal baclofen in ambulatory patients with spastic cerebral palsy. Neurophysiol Clin 2007;37:23-28.

36. Armstrong RW, Steinbok P, Cochrane DD, Kube SD, Fife SE, Farrell K. Intrathecally administered baclofen for the treatment of children with spasticity of cerebral origin. J Neurosurg 1997;87: 409-414.

37. Albright AL, Barry MJ, Shafton DH, Ferson SS. Intrathecal baclofen for generalized dystonia. Dev Med Child Neurol 2001;43: 652-657.

38. Albright AL. Neurosurgical treatment of spasticity and other pediatric movement disorders. J Child Neurol 2003;18 Suppl 1:S67S78.

39. Ivanhoe CB, Francisco GE, McGuire JR, Subramanian T, Grissom SP. Intrathecal baclofen management of poststroke spastic hypertonia: implications for function and quality of life. Arch Phys Med Rehabil 2006;87:1509-1515.

40. Ben Smail D, Peskine A, Roche N, Mailhan L, Thiébaut I, Bussel B. Intrathecal baclofen for treatment of spasticity of multiple sclerosis patients. Mult Scler 2006;12:101-103.

41. Muller H, Zierski J, Dralle D, et al. Pharmacokinetics of intrathecal baclofen. In: Muller H, Zierski J, Penn RD, editors. Local-spinal therapy of spasticity. Berlin: Springer-Verlag, 1988:155-214.

42. Albright AL, Cervi A, Singletary J. Intrathecal baclofen for spasticity in cerebral palsy. JAMA 1991;1418-1422.

43. Kofler M, Kronenberg MF, Rifici C, Saltuari L, Bauer G. Epileptic seizures associated with intrathecal baclofen application. Neurology 1994;44:25-27.

44. Buonaguro V, Scelsa B, Curci D, Monforte S, Iuorno T, Motta F. Epilepsy and intrathecal baclofen therapy in children with cerebral palsy. Pediatric Neurology 2005;33:110-113.

45. Sansone JM, Mann D, Noonan K, Mcleish D, Ward M, Iskandar BJ. Rapid progression of scoliosis following insertion of intrathecal baclofen pump. J Pediatric Orthop 2006;26:125-128.

46. Albright AL, Turner M, Pattisapu JV. Best-practice surgical techniques for intrathecal baclofen therapy. J Neurosurg 2006;104: 233-239.

47. McCall TD, MacDonald JD. Cervical catheter tip placement for intrathecal baclofen administration. Neurosurgery 2006;59:634640.

48. Kopell BH, Sala D, Doyle WK, Feldman DS, Wisoff JH, Weiner HL. Subfascial implantation of intrathecal baclofen pumps in children: technical note. Neurosurgery 2001;49:753-756. 
49. Huntoon MA, Hurdle MF, Marsh RW, Reeves RK. Intrinsic spinal cord catheter placement: implications of new intractable pain in a patient with a spinal cord injury. Anesth Analg 2004;99:17631765.

50. Atiyeh BS, Hayek SN, Skaf GS, Al Araj A, Chamoun RB. Baclofen pump pocket infection: a case report of successful salvage with muscle flap. Int Wound J 2006;3:23-28.

51. Boviatsis EJ, Kouyialis AT, Boutsikakis I, Korfias S, Sakas DE. Infected CNS infusion pumps, Is there a chance for treatment without removal? Acta Neurochir (Wien) 2004;146:463-467.

52. Shirley KW, Kothare S, Piatt JH Jr, Adirim TA. Intrathecal baclofen overdose and withdrawal. Pediatr Emerg Care 2006;22: $258-261$

53. Greenberg MI, Hendrickson RG. Baclofen withdrawal following removal of an intrathecal baclofen pump despite oral baclofen replacement. J Toxicol Clin Toxicol 2003;41:83-85.

54. Wadhwa RK, Shaya MR, Nanda A. Spinal cord compression in a patient with a pain pump for failed back syndrome: a chalk-like precipitate mimicking a spinal cord neoplasm: case report. Neurosurgery 2006;58:E387.

55. Bejjani GK, Karim NO, Tzortzidis F. Intrathecal granuloma after implantation of a morphine pump: case report and review of the literature. Surg Neurol 1997;48:288-291.

56. Miele VJ, Price KO, Bloomfield S, Hogg J, Bailes JE. A review of intrathecal morphine therapy related granulomas. Eur J Pain 2006;10:251-261.
57. Lew SM, Psaty EL, Abbott R. An unusual cause of overdose after baclofen pump implantation: case report. Neurosurgery 2005;56:E624.

58. Lazorthes Y, Verdié JC, Bastide R, Lavados A, Descouens D. Spinal versus intraventricular chronic opiate administration with implantable drug delivery devices for cancer pain. Appl Neurophysiol 1985;48: $234-241$.

59. Lazorthes YR, Sallerin BAM, Verdié JCP. Intracerebroventricular administration of morphine for control of irreducible cancer pain. Neurosurgery 1995;37:422-429.

60. Dennis GC, DeWitty RL. Long-term intraventricular infusion of morphine for intractable pain in cancer of the head and neck. Neurosurgery 1990;26:404-407.

61. Karavelis A, Foroglou G, Selviaridis P, Fountzilas G. Intraventricular administration of morphine for control of intractable cancer pain in 90 patients. Neurosurgery 1996;39:57-61.

62. Baskin DS, Browning JL, Pirozzolo FJ, Korporaal S, Baskin JA, Appel SH. Brain choline acetyltransferase and mental function in Alzheimer disease. Arch Neurol 1999;56:1121-1123.

63. Passini MA, Watson DJ, Vite CH, Landsburg DJ, Feigenbaum AL, Wolfe JH. Intraventricular brain injection of adeno-associated virus type 1 (AAV1) in neonatal mice results in complementary patterns of neuronal transduction to AAV2 and total long-term correction of storage lesions in the brain of $\beta$-glucuronidase-deficient mice. J Virol 2003;77:7034-7040.

64. Dohura K, Ishikawa K, Murakami-Kubo I, et al. Treatment of transmissible spongiform encephalopathy by intraventricular drug infusion in animal models. J Virol 2004;78:4999-5006. 